\title{
The role of myeloid-derived suppressor cells in immune ontogeny
}

\author{
Soren Gantt ${ }^{1}{ }^{*}$, Ana Gervassi ${ }^{2}$, Heather Jaspan ${ }^{2,3}$ and Helen Horton ${ }^{2,4}$ \\ 1 Child and Family Research Institute, University of British Columbia, Vancouver, BC, Canada \\ 2 Seattle BioMed, Seattle, WA, USA \\ ${ }^{3}$ Division of Immunology, University of Cape Town, Cape Town, South Africa \\ ${ }^{4}$ Janssen ID\&V Research and Development, Antwerp, Belgium
}

Edited by:

Arnaud Marchant, Université Libre de Bruxelles, Belgium

Reviewed by:

Bernard Vanhove, Centre National de Recherche Scientifique, France

Stanislas Goriely, Université Libre de Bruxelles, Belgium

*Correspondence:

Soren Gantt, Child and Family

Research Institute, 950 West 28th

Avenue, Vancouver, BC V5Z 4H4,

Canada

e-mail:sgantt@cfri.ca
Myeloid-derived suppressor cells (MDSC) are a heterogeneous population of granulocytic or monocytic cells that suppress innate as well as adaptive immune responses. In healthy adults, immature myeloid cells differentiate into macrophages, dendritic cells, and granulocytes in the bone marrow and MDSC are rarely detected in peripheral blood. However, in certain pathologies, in particular malignancies and chronic infection, differentiation of these cells is altered resulting in accumulation of circulating suppressive myeloid cells. MDSC express suppressive factors such as arginase-1, reactive oxygen species, and inducible nitric oxide synthase, which have the ability to inhibit $T$ cell proliferation and cytoxicity, induce the expansion of regulatory $T$ cells, and block natural killer cell activation. It is increasingly recognized that MDSC alter the immune response to several cancers, and perhaps chronic viral infections, in clinically important ways. In this review, we outline the potential contribution of MDSC to the generation of feto-maternal tolerance and to the ineffective immune responses to many infections and vaccines observed in early postnatal life. Granulocytic MDSC are present in large numbers in pregnant women and in cord blood, and wane rapidly during infancy. Furthermore, cord blood MDSC suppress in vitro T cell and NK responses, suggesting that they may play a significant role in human immune ontogeny. However, there are currently no data that demonstrate in vivo effects of MDSC on feto-maternal tolerance or immune ontogeny. Studies are ongoing to evaluate the functional importance of MDSC, including their effects on control of infection and response to vaccination in infancy. Importantly, several pharmacologic interventions have the potential to reverse MDSC function. Understanding the role of MDSC in infant ontogeny and their mechanisms of action could lead to interventions that reduce mortality due to early-life infections.

Keywords: myeloid-derived suppressor cells, immune ontogeny, feto-maternal tolerance, neonate

\section{INTRODUCTION}

Approximately, one million newborns die due to infection each year worldwide (1). It is increasingly apparent that the extreme vulnerability to infections of neonates and young children is related to substantial changes that the immune system undergoes during early life (2-6). In order to suppress allogeneic responses and pathologic inflammation due to antigenic differences between the fetus and its mother, the feto-maternal environment evolved to be immunosuppressive $(7,8)$, which likely influences post-natal immune responses. Furthermore, specific antigenic exposures or infectious risks that occur at different ages during childhood may have shaped the observed transition to more adult-type immune responses (9). It is clear that nearly all aspects of the neonatal innate and adaptive immune response differ from those of older children and adults; the underlying mechanisms for these differences are multifactorial, and as yet incompletely understood. This review will discuss the potential contribution of myeloid-derived suppressor cells (MDSC) to the ontogeny of the human immune system and early-life immunologic phenotype. MDSC are particularly intriguing because of their plasticity and the availability of agents to reverse their suppressive activity, which could prove valuable for accelerating the ability of young infants to mount protective immune responses to infection or vaccines. As such, we summarize the evidence and outline a proposed agenda of future research on MDSC with respect to newborn and infant immunity.

\section{MDSC CHARACTERIZATION AND PHENOTYPES}

Myeloid lineage progenitors generated in the bone marrow classically differentiate into macrophages, dendritic cells (DC), and granulocytes. The ontogeny of myeloid cells is discussed in detail elsewhere in this issue (De Kleer et al., submitted), and numerous excellent reviews of MDSC in other contexts have been published (10-15). MDSC are not a separate lineage of cells, but are rather a heterogeneous population of activated myeloid cells with suppressive functions. Although suppressive myeloid cells were described more than 30 years ago (16-18), the diverse phenotypes of MDSC and their biological roles have only recently begun to be characterized in detail. These cells are defined by having myeloid markers, 
potent immunosuppressive activity, and for monocytic MDSC, the ability to differentiate into mature macrophages and DC. In mice, there are two relatively distinct subsets of MDSC: monocytic MDSC $\left(\mathrm{CD} 11 \mathrm{~b}^{+} \mathrm{LY}^{-} \mathrm{LY}^{-} \mathrm{LC}^{\text {high }}\right)$ and granulocytic MDSC $\left(\mathrm{CD}_{11 b^{+}} \mathrm{LY6G}^{+}\right.$LY6C $\left.^{\text {low }}\right)(10,13)$. Human MDSC are less easily categorized into monocytic vs. granulocytic because of the lack of a Ly-6G (Gr-1) gene homolog in humans. However, human MDSC have been defined as $\mathrm{CD}_{3}{ }^{+} \mathrm{CD} 11 \mathrm{~b}^{+}$HLA-DR ${ }^{\text {low/- }}$, with monocytic MDSC being CD14 ${ }^{ \pm} \mathrm{CD} 15^{\text {low/- }}$ and granulocytic MDSC being $\mathrm{CD} 14^{-} \mathrm{CD}^{+} 5^{+} \mathrm{CD} 6 \mathrm{~b}^{+}$, which appears consistent with hematologic morphology $(10,13)$. A population of promyelocytic MDSC in bone marrow and several cancers has also been defined by being CD33 ${ }^{+}$HLA-DR $^{-} \mathrm{CD}_{11} \mathrm{~b}^{\text {low/- }} \mathrm{CD}^{-}(15,19)$. MDSC populations appear to be predominantly of the granulocytic type in the setting of cancer, as well as in early infancy, as discussed below. In HIV and other chronic diseases, the relative importance of monocytic and granulocytic MDSC is unclear (11, 20-22). These definitions and classifications are somewhat controversial, however, given the heterogeneity of MDSC populations and the variability in markers used by different groups, and the fact that there may be overlap between MDSC phenotypes $(23,24)$. Furthermore, it is not entirely clear whether or how granulocytic MDSC differ from other subsets of activated mature neutrophils with suppressive activity (25).

\section{SUPPRESSIVE MECHANISIMS}

The hallmark of MDSC is their ability to suppress T cell and NK cell responses. MDSC have been shown to suppress immune responses through a variety of direct mechanisms, including arginase-1, inducible nitric oxide synthase (iNOS), and production of reactive oxygen species (ROS). Both arginase- 1 and iNOS metabolize arginine. In humans, arginase- 1 is primarily expressed in granulocytic MDSC, whereas in mice, arginase- 1 is expressed by both monocytic and granulocytic MDSC (26). However, in both species, the downstream effects of arginase- 1 appear the same. L-arginine is catabolized by arginase- 1 to urea and L-ornithine. In humans, arginine starvation inhibits $\mathrm{T}$ cell proliferation through decreasing $\mathrm{CD} 3 \zeta$-chain expression (27) and preventing the expression of cell-cycle regulators cyclinD3 and cdk4 (28). Taheri et al. first demonstrated that Jurkat $\mathrm{T}$ cells cultured in medium with levels of arginine $<50 \mu \mathrm{M}$ (normal levels of arginine in the serum range between 50 and $150 \mu \mathrm{M}$ ) resulted in the loss of CD3 $\zeta$ expression (29). Down-regulation of TCR $\zeta$-chain is known to be critical for normal $\mathrm{T}$ cell function, including proliferation and IFN $\gamma$ production (30).

MDSC-derived iNOS converts L-arginine to citrulline and NO, which suppresses $\mathrm{T}$ cell function through inhibition of Jak/STAT signaling, reducing MHC class II expression and inducing T cell apoptosis (31-34). ROS and NO produced by MDSC also result in nitration of the $\mathrm{T}$ cell receptor, interfering with recognition of peptide antigens presented by MHC (35). Because cysteine provided by antigen-presenting cells (APC) is required for T cell activation, MDSC also inhibit T cell responses by depleting the pool of cysteine available to APC (36). MDSC can also inhibit T cell responses in a contact-dependent manner, such as through membranebound TGF- $\beta$ (37). Tumor models have also demonstrated direct suppression of NK cell cytotoxicity, NKG2D expression, and IFN- $\gamma$ production by MDSC in a contact-dependent manner $(37,38)$. Arginase- 1 has also been shown to inhibit NK cell proliferation and secretion of IFN- $\gamma$ (39).

Other mechanisms of MDSC suppression in various models and disease states include their expression of program death ligand 1 (PD-L1), CD80/86 (the ligand for CTLA4), and Galectin-9 (the ligand for Tim-3), as well as production of heme oxygenase-1, IL-6, and IL-10 (40-43). In addition to acting on T cells directly, as tolerogenic APCs, MDSC also suppress T cell responses indirectly, through other suppressive cell populations. Regulatory $\mathrm{T}$ cells (Tregs) are recruited and expanded by MDSC production of TGF- $\beta$ and IL-10 and through CD40-CD40L interactions (44$46)$. In addition, IL-10 production by MDSC may also influence $\mathrm{T}$ cell function via macrophages, which produce less IL-12 and predispose to Th2-type responses (47).

\section{EXPANSION AND ROLE IN PATHOLOGIC CONDITIONS}

In healthy adults, immature myeloid cells that are generated in the bone marrow differentiate into mature, functional macrophages, DC, and granulocytes. However, in certain pathologic conditions, in particular cancer, there is accumulation and activation of MDSC that can potently suppress T cell and NK cell function $(10,12,13)$. In addition to their importance in cancer pathogenesis, studies demonstrate a role for MDSC suppressive function during chronic infections/inflammation, sepsis, transplant, and trauma (11, 22, 48-51). In particular, the suppressive effects of MDSC appear to impair control of chronic viral infections, both in mouse models using lymphocytic choriomeningitis virus and vesicular stomatitis virus, as well as in observational human studies of HIV and hepatitis $C$ virus infections $(11,52)$. MDSC expand and become activated in response to a variety of factors, including inflammatory cytokines (IL-6, VEGF), other pro-inflammatory factors (COX2 and prostaglandin $\mathrm{E}_{2}\left(\mathrm{PGE}_{2}\right), \mathrm{GM}-\mathrm{CSF}, \mathrm{M}-\mathrm{CSF}$, stem cell factor (SCF)-1 (10, 12, 13). In addition, MDSC may also be increased in elderly mice (53) and humans (54), which might be involved with the phenomena of immunosenescence and "inflammaging."

Although induction of MDSC may be a normal physiologic response to inflammation, there is convincing evidence that they can be deleterious in malignant conditions (12-14). A number of chemotherapeutic interventions that target MDSC are being studied. Agents that decrease MDSC number include sunitinib, gemcitabine, and docetaxel; other drugs, such as COX-2 inhibitors and the phosphodiesterase-5 inhibitor sildenafil, appear to inhibit MDSC function $(12,14,15)$. Perhaps most interestingly, use of ATRA (all-trans retinoic acid) $(55,56)$ or vitamin D3 $(57,58)$ has been shown to drive maturation of MDSC into fully functional stimulatory monocytes and DC.

\section{ROLE IN FETO-MATERNAL TOLERANCE AND IMIMUNE ONTOGENY}

There are clear differences in both innate and adaptive immune responses between neonates and older children or adults (2-6, 59). The fetus is antigenically different from its mother, and is thus analogous to a semi-allogeneic transplant, with the risk of immunologic rejection $(7,8)$. The fetal immune system is biased toward tolerogenic responses, as is that of the pregnant woman. Thus, the immune response during pregnancy appears to have 
evolved to prevent potentially damaging inflammation that may result in abortion or pre-term delivery. Furthermore, early postnatal tolerance might prevent damaging inflammation due to microbial colonization or environmental antigens in extrauterine life (60). Although the immunologic state of the fetus and newborn might be evolutionarily advantageous, evidence suggests that it predisposes to severe infections, especially those due to intracellular pathogens, and impairs responses to vaccinations in post-natal life $(9,59,61)$. Innate immune cells - monocytes, DC, NK cells - respond differently in neonates compared to later in life, and this contributes to their vulnerability to infection $(9,62-$ 66). In addition to altered innate immunity, adaptive responses are also qualitatively different in early life $(61,67-70)$. These differences likely in part reflect the innate neonatal response. However, neonatal $\mathrm{T}$ cells may also have intrinsic differences, with $\mathrm{CD} 4{ }^{+} \mathrm{T}$ cell being biased toward Th2 responses and $\mathrm{CD}^{+}$effector $\mathrm{T}$ cells may be particularly short-lived $(71,72)$. As described elsewhere in this issue, multiple interrelated mechanisms likely contribute to the quality of the immune responses observed in utero and during early life. Included among them are suppressor cell populations, such as Tregs in the fetus (73), a novel immunosuppressive CD71 ${ }^{+}$ erythroid cell type in newborns (60), and others (74). Preliminary findings suggest that MDSC may also contribute to feto-maternal tolerance and infant immune ontogeny.

Recent studies by Rieber et al. and by our own group have found that MDSC are present in high numbers in cord blood (75-77). As opposed to healthy adults, in whom $<1 \%$ of PBMC are MDSC, CBMC of healthy neonates has a median of approximately $5 \%$ MDSC, comparable to frequencies observed in PBMC of cancer patients. Of note, there is substantial variation between individual neonates, suggesting that observational studies to determine associations between MDSC frequency or activity and clinical outcomes, such as response to vaccines or infection, are feasible. Cord blood MDSC are predominantly of the granulocytic type, based on CD66b and/or CD15, arginase-1 expression, and lack of CD14 expression, as well as by microscopic examination of purified cord blood MDSC, which demonstrated the appearance of neutrophils at various stages of maturation (75-77). Furthermore, granulocytic MDSC in cord blood were shown to potently suppress both $\mathrm{T}$ cell and NK cell responses in vitro, using depletion and add-back experiments. We and Rieber et al. also examined MDSC levels during infancy and early childhood by cross-sectional sampling of healthy pediatric subjects and found that MDSC likely decay to adult levels within the first few months of life (75-77).

These findings raise the possibility that MDSC are at least one of the mechanisms by which feto-maternal tolerance is maintained and that may underlie why neonates have impaired T cell and NK cell immunity (Figure 1). Although the possibility that MDSC suppress infant immune responses in vivo is highly speculative at this time, it is notable that the neonatal immune environment may be particularly prone to support the generation of MDSC. Multiple factors implicated in the expansion or activation of MDSC, including IL- 10 , IL- 6 , and TGF- $\beta$, are all increased in neonates $(65,78,79)$ or fetal tissue (73). In addition, MDSC have been demonstrated to promote the development of Tregs (44-46), which are highly prevalent in the fetus and have documented importance in fetomaternal tolerance $(73,80-82)$. On the maternal side, higher rates of metastasis during gestation in a mouse model of melanoma was attributed to an accumulation of MDSC and their inhibition of NK cell activity (83). The potential importance of maternal MDSC in the mouse is also highlighted by studies indicating that progesterone increases MDSC (84) and that Tim-3 blockade experiments that result in fetal rejection lead to MDSC expansion (85). Finally, preliminary studies in humans have found high frequencies of MDSC in the placenta and in peripheral blood of pregnant women compared to non-pregnant controls $(86,87)$.

\section{CONCLUSION AND SUGGESTIONS FOR FUTURE RESEARCH}

The specific limitations of the neonatal immune response have been implicated in the high rate of morbidity from infections in newborns and young infants. Thus, in order to reduce the enormous global burden of infant mortality due to infection, it is
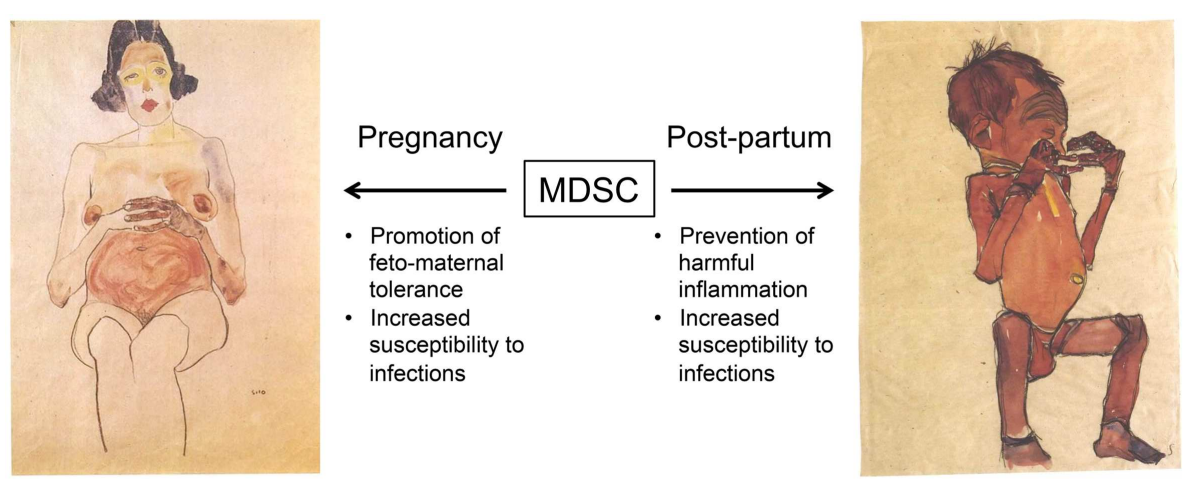

FIGURE 1 | Proposed roles of myeloid-derived suppressor cells (MDSC) during gestation and early post-natal life. We hypothesize that an increased frequency of MDSC promotes feto-maternal tolerance during gestation. Very little is known about the expansion of maternal or fetal MDSC, or how this may be affected by the degree of HLA discordance or other factors. High levels of MDSC persist in the infant at birth, and may suppress harmful inflammation due to microbial colonization and exposure to environmental antigens. However, this may also impair the generation of protective immune responses against infections. Images by Egon Schiele (1890 - 1918), obtained through Wikimedia Commons (http://commons.wikimedia.org). Left, Red nude, pregnant (Roter akt, schwanger) 1910, private collection. Right, Newborn hiding its face with its hands (Neugeborenes die hände vor das gesicht haltend) 1910, Leopold Museum, Vienna. 
critical to define the mechanisms behind reduced neonatal immunity, and to identify new ways of enhancing protective immune responses in early life. Undeniably, any interventions along these lines must be approached with extreme caution in order to ensure the safety of this vulnerable population. MDSC are unambiguously important in suppressing immune responses in a variety of pathological conditions. As detailed above, it appears possible that MDSC also contribute to feto-maternal tolerance. Furthermore, MDSC may modulate early-life immune responses. We speculate that MDSC may be beneficial post-natally for preventing inflammation during colonization and microbiome establishment. However, this dampened immunity may be detrimental for mounting protective responses to vaccination and pathogenic infection. The potential of MDSC to modulate immunity in premature or young infants is particularly intriguing given the availability of drugs e.g., retinoids, vitamin D3, sildenafil - that might be able to counteract the suppressive effects of MDSC. Indeed, if MDSC suppress protective immune responses in early infancy, it is conceivable that interventions already in wide use, e.g., vitamin A supplementation $(88,89)$ might affect infant health through effects on MDSC. It is also interesting to speculate that MDSC contribute to the decreased risk of graft-vs.-host disease in stem cell transplant recipients of cord blood compared to bone marrow grafts (90) or might have other therapeutic uses.

Much additional study is needed to determine whether MDSC are important in immune ontogeny, and if they might be useful targets for therapies to reduce infectious mortality in infants. Longitudinal studies of premature and term neonates are required to define the natural history and, imperatively, the physiological relevance of MDSC during early life. These cohort studies should assess not only the frequency of MDSC at different ages, but measure clinically important outcomes, such as vaccine responses and/or infectious outcomes. Importantly, such work should be performed in populations with high rates of infection and infant mortality, to ensure generalizability, and public health relevance. These studies are made more challenging by the fact that MDSC are cryosensitive, which currently necessitates testing fresh blood (91). Mouse or other animal models may also be especially useful to help evaluate the potential importance and mechanism of MDSC immune suppression during gestation and early post-natal life. Though much is known about the mechanisms of action of MDSC in cancer and other pathologic states, many questions remain, and it is unknown whether these same mechanisms can be extrapolated to MDSC functions during fetal or early post-natal life. Work is also needed to better understand the potential relationship between MDSC and neonatal APC responses, and whether MDSC interact with other suppressor cell populations of importance in immune ontogeny (Tregs, CD71 ${ }^{+}$erythroid cells, etc.).

In summary, recent studies suggest that MDSC are prevalent and may suppress immune responses in early life. If so, MDSC could represent one important part of the complex process of immune ontogeny and feto-maternal tolerance. In addition to their fundamental biology, these cells are of particular interest because their function can be modulated with several drugs that are widely used, whose effects on MDSC are already being evaluated in other clinical contexts. As such, future research in this field holds substantial promise.

\section{ACKNOWLEDGMENTS}

We thank Nick Lejarcegui, Elvis Kidzeru, and Amanda Jacobson for their technical assistance. This work was supported by grants from the NIH: R01 AI100018 and K08 HD069201.

\section{REFERENCES}

1. Blencowe $\mathrm{H}$, Cousens $\mathrm{S}$. Addressing the challenge of neonatal mortality. Trop Med Int Health (2013) 18:303-12. doi:10.1111/tmi.12048

2. Wilson $\mathrm{CB}$, Lewis $\mathrm{DB}$. Basis and implications of selectively diminished cytokine production in neonatal susceptibility to infection. Rev Infect Dis (1990) 12(Suppl 4):S410-20. doi:10.1093/clinids/12.Supplement_4.S410

3. Kovarik J, Siegrist CA. Immunity in early life. Immunol Today (1998) 19:150-2. doi:10.1016/S0167-5699(97)01230-9

4. Levy O. Innate immunity of the newborn: basic mechanisms and clinical correlates. Nat Rev Immunol (2007) 7:379-90. doi:10.1038/nri2075

5. Philbin VJ, Levy O. Developmental biology of the innate immune response: implications for neonatal and infant vaccine development. Pediatr Res (2009) 65:98R-105R. doi:10.1203/PDR.0b013e31819f195d

6. Prendergast AJ, Klenerman P, Goulder PJ. The impact of differential antiviral immunity in children and adults. Nat Rev Immunol (2012) 12:636-48. doi: $10.1038 /$ nri3277

7. Makrigiannakis A, Karamouti M, Drakakis P, Loutradis D, Antsaklis A. Fetomaternal immunotolerance. Am J Reprod Immunol (2008) 60:482-96. doi:10.1111/ j.1600-0897.2008.00655.x

8. Erlebacher A. Immunology of the maternal-fetal interface. Annu Rev Immunol (2013) 31:387-411. doi:10.1146/annurev-immunol-032712-100003

9. Kollmann TR, Levy O, Montgomery RR, Goriely S. Innate immune function by Toll-like receptors: distinct responses in newborns and the elderly. Immunity (2012) 37:771-83. doi:10.1016/j.immuni.2012.10.014

10. Gabrilovich DI, Nagaraj S. Myeloid-derived suppressor cells as regulators of the immune system. Nat Rev Immunol (2009) 9:162-74. doi:10.1038/nri2506

11. Goh C, Narayanan S, Hahn YS. Myeloid-derived suppressor cells: the dark knight or the joker in viral infections? Immunol Rev (2013) 255:210-21. doi:10.1111/imr.12084

12. Albeituni SH, Ding C, Yan J. Hampering immune suppressors: therapeutic targeting of myeloid-derived suppressor cells in cancer. Cancer J (2013) 19:490-501. doi:10.1097/PPO.0000000000000006

13. Serafini P. Myeloid derived suppressor cells in physiological and pathological conditions: the good, the bad, and the ugly. Immunol Res (2013) 57:172-84. doi:10.1007/s12026-013-8455-2

14. Najjar YG, Finke JH. Clinical perspectives on targeting of myeloid derived suppressor cells in the treatment of cancer. Front Oncol (2013) 3:49. doi:10.3389/ fonc.2013.00049

15. Diaz-Montero CM, Finke J, Montero AJ. Myeloid-derived suppressor cells in cancer: therapeutic, predictive, and prognostic implications. Semin Oncol (2014) 41:174-84. doi:10.1053/j.seminoncol.2014.02.003

16. Strober S, Okada S, Oseroff A. Role of natural suppressor cells in allograft tolerance. Fed Proc (1984) 43:263-5.

17. Buessow SC, Paul RD, Lopez DM. Influence of mammary tumor progression on phenotype and function of spleen and in situ lymphocytes in mice. J Natl Cancer Inst (1984) 73:249-55.

18. Young MR, Endicott RA, Duffie GP, Wepsic HT. Suppressor alveolar macrophages in mice bearing metastatic Lewis lung carcinoma tumors. J Leukoc Biol (1987) 42:682-8.

19. Solito S, Falisi E, Diaz-Montero CM, Doni A, Pinton L, Rosato A, et al. A human promyelocytic-like population is responsible for the immune suppression mediated by myeloid-derived suppressor cells. Blood (2011) 118:2254-65. doi:10.1182/blood-2010-12-325753

20. Qin A, Cai W, Pan T, Wu K, Yang Q, Wang N, et al. Expansion of monocytic myeloid-derived suppressor cells dampens T cell function in HIV-1-seropositive individuals. J Virol (2013) 87:1477-90. doi:10.1128/JVI.01759-12

21. Vollbrecht T, Stirner R, Tufman A, Roider J, Huber RM, Bogner JR, et al. Chronic progressive HIV-1 infection is associated with elevated levels of myeloidderived suppressor cells. AIDS (2012) 26:F31-7. doi:10.1097/QAD. 0b013e328354b43f

22. du Plessis N, Loebenberg L, Kriel M, von Groote-Bidlingmaier F, Ribechini E, Loxton AG, et al. Increased frequency of myeloid-derived suppressor cells during active tuberculosis and after recent mycobacterium tuberculosis infection 
suppresses T-cell function. Am J Respir Crit Care Med (2013) 188:724-32. doi:10.1164/rccm.201302-0249OC

23. Gabrilovich DI, Bronte V, Chen SH, Colombo MP, Ochoa A, Ostrand-Rosenberg $\mathrm{S}$, et al. The terminology issue for myeloid-derived suppressor cells. Cancer Res (2007) 67:425. doi:10.1158/0008-5472.CAN-06-3037

24. Peranzoni E, Zilio S, Marigo I, Dolcetti L, Zanovello P, Mandruzzato S, et al. Myeloid-derived suppressor cell heterogeneity and subset definition. Curr Opin Immunol (2010) 22:238-44. doi:10.1016/j.coi.2010.01.021

25. Pillay J, Tak T, Kamp VM, Koenderman L. Immune suppression by neutrophils and granulocytic myeloid-derived suppressor cells: similarities and differences. Cell Mol Life Sci (2013) 70:3813-27. doi:10.1007/s00018-013-1286-4

26. Popovic PJ, Zeh HJ III, Ochoa JB. Arginine and immunity. J Nutr (2007) 137:1681S-6S.

27. Rodriguez PC, Quiceno DG, Zabaleta J, Ortiz B, Zea AH, Piazuelo MB, et al. Arginase I production in the tumor microenvironment by mature myeloid cells inhibits T-cell receptor expression and antigen-specific T-cell responses. Cancer Res (2004) 64:5839-49. doi:10.1158/0008-5472.CAN-04-0465

28. Rodriguez PC, Quiceno DG, Ochoa AC. L-arginine availability regulates Tlymphocyte cell-cycle progression. Blood (2007) 109:1568-73. doi:10.1182/ blood-2006-06-031856

29. Taheri F, Ochoa JB, Faghiri Z, Culotta K, Park HJ, Lan MS, et al. L-Arginine regulates the expression of the T-cell receptor zeta chain (CD3zeta) in Jurkat cells. Clin Cancer Res (2001) 7:958s-65s.

30. Baniyash M. TCR zeta-chain downregulation: curtailing an excessive inflammatory immune response. Nat Rev Immunol (2004) 4:675-87. doi:10.1038/nri1434

31. Mannick JB, Hausladen A, Liu L, Hess DT, Zeng M, Miao QX, et al. Fasinduced caspase denitrosylation. Science (1999) 284:651-4. doi:10.1126/science. 284.5414.651

32. Bingisser RM, Tilbrook PA, Holt PG, Kees UR. Macrophage-derived nitric oxide regulates $\mathrm{T}$ cell activation via reversible disruption of the Jak3/STAT5 signaling pathway. J Immunol (1998) 160:5729-34.

33. Harari O, Liao JK. Inhibition of MHC II gene transcription by nitric oxide and antioxidants. Curr Pharm Des (2004) 10:893-8. doi:10.2174/ 1381612043452893

34. Rivoltini L, Carrabba M, Huber V, Castelli C, Novellino L, Dalerba P, et al. Immunity to cancer: attack and escape in T lymphocyte-tumor cell interaction. Immunol Rev (2002) 188:97-113. doi:10.1034/j.1600-065X.2002.18809.x

35. Condamine T, Gabrilovich DI. Molecular mechanisms regulating myeloidderived suppressor cell differentiation and function. Trends Immunol (2011) 32:19-25. doi:10.1016/j.it.2010.10.002

36. Srivastava MK, Sinha P, Clements VK, Rodriguez P, Ostrand-Rosenberg S. Myeloid-derived suppressor cells inhibit T-cell activation by depleting cystine and cysteine. Cancer Res (2010) 70:68-77. doi:10.1158/0008-5472.CAN-092587

37. Li H, Han Y, Guo Q, Zhang M, Cao X. Cancer-expanded myeloid-derived suppressor cells induce anergy of NK cells through membrane-bound TGF-beta 1. J Immunol (2009) 182:240-9. doi:10.4049/jimmunol.182.1.240

38. Liu C, Yu S, Kappes J, Wang J, Grizzle WE, Zinn KR, et al. Expansion of spleen myeloid suppressor cells represses NK cell cytotoxicity in tumor-bearing host. Blood (2007) 109:4336-42. doi:10.1182/blood-2006-09-046201

39. Oberlies J, Watzl C, Giese T, Luckner C, Kropf P, Muller I, et al. Regulation of NK cell function by human granulocyte arginase. J Immunol (2009) 182:5259-67. doi:10.4049/jimmunol.0803523

40. Noman MZ, Desantis G, Janji B, Hasmim M, Karray S, Dessen P, et al. PD-L1 is a novel direct target of HIF-1 $\alpha$, and its blockade under hypoxia enhanced MDSC-mediated T cell activation. J Exp Med (2014) 211:781-90. doi:10.1084/jem.20131916

41. De Wilde V, Van Rompaey N, Hill M, Lebrun JF, Lemaitre P, Lhomme $\mathrm{F}$, et al. Endotoxin-induced myeloid-derived suppressor cells inhibit alloimmune responses via heme oxygenase-1. Am J Transplant (2009) 9:2034-47. doi:10.1111/j.1600-6143.2009.02757.x

42. Sumida K, Wakita D, Narita Y, Masuko K, Terada S, Watanabe K, et al. AntiIL-6 receptor mAb eliminates myeloid-derived suppressor cells and inhibits tumor growth by enhancing T-cell responses. Eur J Immunol (2012) 42:2060-72. doi:10.1002/eji.201142335

43. Dugast AS, Haudebourg T, Coulon F, Heslan M, Haspot F, Poirier N, et al. Myeloid-derived suppressor cells accumulate in kidney allograft tolerance and specifically suppress effector T cell expansion. J Immunol (2008) 180:7898-906. doi:10.4049/jimmunol.180.12.7898
44. Serafini P, Mgebroff S, Noonan K, Borrello I. Myeloid-derived suppressor cells promote cross-tolerance in B-cell lymphoma by expanding regulatory $\mathrm{T}$ cells. Cancer Res (2008) 68:5439-49. doi:10.1158/0008-5472.CAN-07-6621

45. Huang B, Pan PY, Li Q, Sato AI, Levy DE, Bromberg J, et al. Gr-1+CD115+ immature myeloid suppressor cells mediate the development of tumor-induced $\mathrm{T}$ regulatory cells and T-cell anergy in tumor-bearing host. Cancer Res (2006) 66:1123-31. doi:10.1158/0008-5472.CAN-05-1299

46. Hoechst B, Ormandy LA, Ballmaier M, Lehner F, Kruger C, Manns MP, et al. A new population of myeloid-derived suppressor cells in hepatocellular carcinoma patients induces CD4(+)CD25(+)Foxp3(+) T cells. Gastroenterology (2008) 135:234-43. doi:10.1053/j.gastro.2008.03.020

47. Sinha P, Clements VK, Bunt SK, Albelda SM, Ostrand-Rosenberg S. Cross-talk between myeloid-derived suppressor cells and macrophages subverts tumor immunity toward a type 2 response. J Immunol (2007) 179:977-83. doi:10.4049/ jimmunol.179.2.977

48. Van Rompaey N, Le Moine A. Myeloid-derived suppressor cells: characterization and expansion in models of endotoxemia and transplantation. Methods Mol Biol (2011) 677:169-80. doi:10.1007/978-1-60761-869-0_12

49. Arocena AR, Onofrio LI, Pellegrini AV, Carrera Silva AE, Paroli A, Cano RC, et al. Myeloid-derived suppressor cells are key players in the resolution of inflammation during a model of acute infection. Eur J Immunol (2014) 44:184-94. doi:10.1002/eji.201343606

50. Li RJ, Liu L, Gao W, Song XZ, Bai XJ, Li ZF. Cyclooxygenase-2 blockade inhibits accumulation and function of myeloid-derived suppressor cells and restores $\mathrm{T}$ cell response after traumatic stress. Journal of Huazhong University of Science and Technology (2014) 34:234-40. doi:10.1007/s11596-014-1264-6

51. Cuenca AG, Delano MJ, Kelly-Scumpia KM, Moreno C, Scumpia PO, Laface DM, et al. A paradoxical role for myeloid-derived suppressor cells in sepsis and trauma. Mol Med (2011) 17:281-92. doi:10.2119/molmed.2010.00178

52. Norris BA, Uebelhoer LS, Nakaya HI, Price AA, Grakoui A, Pulendran B. Chronic but not acute virus infection induces sustained expansion of myeloid suppressor cell numbers that inhibit viral-specific T cell immunity. Immunity (2013) 38:309-21. doi:10.1016/j.immuni.2012.10.022

53. Enioutina EY, Bareyan D, Daynes RA. A role for immature myeloid cells in immune senescence. J Immunol (2011) 186:697-707. doi:10.4049/jimmunol. 1002987

54. Verschoor CP, Johnstone J, Millar J, Dorrington MG, Habibagahi M, Lelic A, et al. Blood CD33(+)HLA-DR(-) myeloid-derived suppressor cells are increased with age and a history of cancer. J Leukoc Biol (2013) 93:633-7. doi:10.1189/jlb. 0912461

55. Kusmartsev S, Su Z, Heiser A, Dannull J, Eruslanov E, Kubler H, et al. Reversal of myeloid cell-mediated immunosuppression in patients with metastatic renal cell carcinoma. Clin Cancer Res (2008) 14:8270-8. doi:10.1158/1078-0432.CCR-080165

56. Mirza N, Fishman M, Fricke I, Dunn M, Neuger AM, Frost TJ, et al. All-transretinoic acid improves differentiation of myeloid cells and immune response in cancer patients. Cancer Res (2006) 66:9299-307. doi:10.1158/0008-5472.CAN06- 1690

57. Lathers DM, Clark JI, Achille NJ, Young MR. Phase 1B study to improve immune responses in head and neck cancer patients using escalating doses of 25-hydroxyvitamin D3. Cancer Immunol Immunother (2004) 53:422-30. doi:10.1007/s00262-003-0459-7

58. Ugel S, Delpozzo F, Desantis G, Papalini F, Simonato F, Sonda N, et al. Therapeutic targeting of myeloid-derived suppressor cells. Curr Opin Pharmacol (2009) 9:470-81. doi:10.1016/j.coph.2009.06.014

59. Dowling DJ, Levy O. Ontogeny of early life immunity. Trends Immunol (2014) 35:299-310. doi:10.1016/j.it.2014.04.007

60. Elahi S, Ertelt JM, Kinder JM, Jiang TT, Zhang X, Xin L, et al. Immunosuppressive CD71+ erythroid cells compromise neonatal host defence against infection. Nature (2013) 504:158-62. doi:10.1038/nature12675

61. Siegrist CA. Neonatal and early life vaccinology. Vaccine (2001) 19:3331-46. doi:10.1016/S0264-410X(01)00028-7

62. Yabuhara A, Kawai H, Komiyama A. Development of natural killer cytotoxicity during childhood: marked increases in number of natural killer cells with adequate cytotoxic abilities during infancy to early childhood. Pediatr Res (1990) 28:316-22. doi:10.1203/00006450-199010000-00002

63. Dominguez E, Madrigal JA, Layrisse Z, Cohen SB. Fetal natural killer cell function is suppressed. Immunology (1998) 94:109-14. doi:10.1046/j.1365-2567. 1998.00489.x 
64. Kenzel S, Henneke P. The innate immune system and its relevance to neonatal sepsis. Curr Opin Infect Dis (2006) 19:264-70. doi:10.1097/01.qco.0000224821. 27482.bd

65. Kollmann TR, Crabtree J, Rein-Weston A, Blimkie D, Thommai F, Wang XY, et al. Neonatal innate TLR-mediated responses are distinct from those of adults. J Immunol (2009) 183:7150-60. doi:10.4049/jimmunol.0901481

66. Jacobson A, Bell F, Lejarcegui N, Mitchell C, Frenkel L, Horton H. Healthy Neonates Possess a CD56-Negative NK Cell Population with Reduced Anti-Viral Activity. PLoS One (2013) 8:e67700. doi:10.1371/journal.pone.0067700

67. Bertotto A, Gerli R, Lanfrancone L, Crupi S, Arcangeli C, Cernetti C, et al. Activation of cord T lymphocytes. II. Cellular and molecular analysis of the defective response induced by anti-CD3 monoclonal antibody. Cell Immunol (1990) 127:247-59. doi:10.1016/0008-8749(90)90130-J

68. Pirenne-Ansart H, Paillard F, De Groote D, Eljaafari A, Le Gac S, Blot P, et al. Defective cytokine expression but adult-type T-cell receptor, CD8, and p56lck modulation in CD3- or CD2-activated T cells from neonates. Pediatr Res (1995) 37:64-9. doi:10.1203/00006450-199501000-00013

69. Wu CY, Demeure C, Kiniwa M, Gately M, Delespesse G. IL-12 induces the production of IFN-gamma by neonatal human CD4 T cells. J Immunol (1993) 151:1938-49.

70. Burchett SK, Corey L, Mohan KM, Westall J, Ashley R, Wilson CB. Diminished interferon-gamma and lymphocyte proliferation in neonatal and postpartum primary herpes simplex virus infection. J Infect Dis (1992) 165:813-8. doi:10.1093/infdis/165.5.813

71. Zaghouani H, Hoeman CM, Adkins B. Neonatal immunity: faulty T-helpers and the shortcomings of dendritic cells. Trends Immunol (2009) 30:585-91. doi:10.1016/j.it.2009.09.002

72. Smith NL, Wissink E, Wang J, Pinello JF, Davenport MP, Grimson A, et al. Rapid Proliferation and Differentiation Impairs the Development of Memory CD8+ T Cells in Early Life. J Immunol (2014) 193:177-84. doi:10.4049/jimmunol. 1400553

73. Mold JE, Michaëlsson J, Burt TD, Muench MO, Beckerman KP, Busch MP, et al. Maternal alloantigens promote the development of tolerogenic fetal regulatory T cells in utero. Science (2008) 322:1562-5. doi:10.1126/science.1164511

74. Gervassi A, Horton H. Is infant immunity actively suppressed or immature? Virology (2014) 2014:1-9. doi:10.4137/VRT.S12248

75. Rieber N, Gille C, Kostlin N, Schafer I, Spring B, Ost M, et al. Neutrophilic myeloid-derived suppressor cells in cord blood modulate innate and adaptive immune responses. Clin Exp Immunol (2013) 174:45-52. doi:10.1111/cei.12143

76. Gervassi A, Lejarcegui N, Dross S, Jacobson A, Gantt S, Jaspan H, et al. Early Life Immunity and Ability to Respond to Vaccines Hindered by Myeloid Derived Suppressor Cells: Implications for Infant HIV Vaccinology. Barcelona: AIDS Vaccine Mary Ann Liebert, Inc (2013). p. A152-3.

77. Gervassi A, Lejarcegui N, Dross S, Jacobson A, Itaya G, Kidzeru E, et al. Myeloid derived suppressor cells are present at high frequency in neonates and suppress in vitro T cell responses PLOS ONE (in press).

78. Angelone DF, Wessels MR, Coughlin M, Suter EE, Valentini P, Kalish LA, et al. Innate immunity of the human newborn is polarized toward a high ratio of IL-6/TNF-alpha production in vitro and in vivo. Pediatr Res (2006) 60:205-9. doi:10.1203/01.pdr.0000228319.10481.ea

79. Marodi L. Innate cellular immune responses in newborns. Clin Immunol (2006) 118:137-44. doi:10.1016/j.clim.2005.10.012

80. Aluvihare VR, Kallikourdis M, Betz AG. Regulatory T cells mediate maternal tolerance to the fetus. Nat Immunol (2004) 5:266-71. doi:10.1038/ni1037

81. Michaelsson J, Mold JE, McCune JM, Nixon DF. Regulation of T cell responses in the developing human fetus. J Immunol (2006) 176:5741-8. doi:10.4049/ jimmunol.176.10.5741
82. Rowe JH, Ertelt JM, Xin L, Way SS. Pregnancy imprints regulatory memory that sustains anergy to fetal antigen. Nature (2012) 490:102-6. doi:10.1038/ nature 11462

83. Mauti LA, Le Bitoux MA, Baumer K, Stehle JC, Golshayan D, Provero P, et al. Myeloid-derived suppressor cells are implicated in regulating permissiveness for tumor metastasis during mouse gestation. J Clin Invest (2011) 121:2794-807. doi:10.1172/JCI41936

84. Spallanzani RG, Dalotto-Moreno T, Raffo Iraolagoitia XL, Ziblat A, Domaica CI, Avila DE, et al. Expansion of CD11b(+)Ly6G (+)Ly6C (int) cells driven by medroxyprogesterone acetate in mice bearing breast tumors restrains NK cell effector functions. Cancer Immunol Immunother (2013) 62:1781-95. doi:10.1007/s00262-013-1483-x

85. Chabtini L, Mfarrej B, Mounayar M, Zhu B, Batal I, Dakle PJ, et al. TIM-3 regulates innate immune cells to induce fetomaternal tolerance. J Immunol (2013) 190:88-96. doi:10.4049/jimmunol.1202176

86. Kropf P, Baud D, Marshall SE, Munder M, Mosley A, Fuentes JM, et al. Arginase activity mediates reversible $\mathrm{T}$ cell hyporesponsiveness in human pregnancy. Eur J Immunol (2007) 37:935-45. doi:10.1002/eji.200636542

87. Köstlin N, Kugel H, Spring B, Leiber A, Marmé A, Henes M, et al. Granulocytic myeloid derived suppressor cells expand in human pregnancy and modulate T-cell responses. Eur J Immunol (2014). doi:10.1002/eji.201344200

88. Klemm RD, Labrique AB, Christian P, Rashid M, Shamim AA, Katz J, et al. Newborn vitamin A supplementation reduced infant mortality in rural Bangladesh. Pediatrics (2008) 122:e242-50. doi:10.1542/peds.2007-3448

89. Awasthi S, Peto R, Read S, Clark S, Pande V, Bundy D, et al. Vitamin A supplementation every 6 months with retinol in 1 million pre-school children in north India: DEVTA, a cluster-randomised trial. Lancet (2013) 381:1469-77. doi:10.1016/S0140-6736(12)62126-6

90. Rocha V, Wagner JE Jr., Sobocinski KA, Klein JP, Zhang MJ, Horowitz MM, et al. Graft-versus-host disease in children who have received a cord-blood or bone marrow transplant from an HLA-identical sibling. Eurocord and International Bone Marrow Transplant Registry Working Committee on Alternative Donor and Stem Cell Sources. N Engl J Med (2000) 342:1846-54. doi:10.1056/NEJM200006223422501

91. Trellakis S, Bruderek K, Hutte J, Elian M, Hoffmann TK, Lang S, et al. Granulocytic myeloid-derived suppressor cells are cryosensitive and their frequency does not correlate with serum concentrations of colony-stimulating factors in head and neck cancer. Innate Immun (2013) 19:328-36. doi:10.1177/ 1753425912463618

Conflict of Interest Statement: The authors declare that the research was conducted in the absence of any commercial or financial relationships that could be construed as a potential conflict of interest.

Received: 30 May 2014; accepted: 29 July 2014; published online: 13 August 2014. Citation: Gantt S, Gervassi A, Jaspan H and Horton $H$ (2014) The role of myeloid-derived suppressor cells in immune ontogeny. Front. Immunol. 5:387. doi: 10.3389/fimmu.2014.00387

This article was submitted to Immunotherapies and Vaccines, a section of the journal Frontiers in Immunology.

Copyright (c) 2014 Gantt, Gervassi, Jaspan and Horton. This is an open-access article distributed under the terms of the Creative Commons Attribution License (CC BY). The use, distribution or reproduction in other forums is permitted, provided the original author(s) or licensor are credited and that the original publication in this journal is cited, in accordance with accepted academic practice. No use, distribution or reproduction is permitted which does not comply with these terms. 